\title{
Hepatitis C Virus Detection in the Semen of Infected Patients
}

Norma de Paula Cavalheiro, Ana Carolina de Oliveira Santos, Carlos Eduardo Melo, Suzana Rie Morimitsu and Antonio Alci Barone Laboratory of Hepatitis LIM-47 - Department of Infectious Diseases of Clinical Hospital of University of São Paulo; São Paulo, SP, Brazil

\begin{abstract}
Though HCV infection is a serious public health problem, some aspects of its biology are still not well understood, such as its transmission through seminal fluid and sexual transmission. We looked for HCV in the semen of infected patients. Thirteen patients were included. Semen fractions (seminal plasma, leukocytes and spermatozoa) were separated with $45 \%$ and $90 \%$ Percoll gradients. The HCV-RNA in blood and semen fractions was extracted using the same protocol (AMPLICOR Roche) and was detected using the qualitative Roche Amplicor test and by agarose gel electrophoresis, with ethidium bromide staining. The mean age of the patients was 40.7 years. Risk factors for the acquisition of HCV included injectable and inhaled drug use in six (42.8\%), blood transfusion in four (28.6\%), and no risk factors in four $(\mathbf{2 8 . 6 \%})$ patients. Genotype 1 was detected in $62 \%$ of the patients, followed by genotype 3 in $23 \%$ and genotype 2 in $15 \%$. All blood samples were positive, regardless of the technique used for detection. All semen samples identified by Roche Amplicor and analyzed by agarose gel electrophoresis were negative. Among the 52 semen samples (total and fractions) identified by the Roche Amplicor method, 45 (87\%) were inhibited. A negative result was recorded for one $(\mathbf{1 . 9 \% )}$ ) total semen sample, one $(1.9 \%)$ leukocyte and four $(7.7 \%)$ seminal plasma fractions. Only one $(\mathbf{1 . 9 \% )}$ ) sample of the spermatozoon fraction was positive. The results obtained suggested false-negative reactions for the semen samples.

Key-Words: HCV, PCR, sexual transmission, semen.
\end{abstract}

Various studies suggest that the risk of sexual transmission of hepatitis $\mathrm{C}$ virus (HCV) is minimal or even inexistent, with its incidence ranging from 0 to $3 \%[1,2]$. The first report discussing the sexual transmission of HCV, in which multiple sex partners were considered to be a risk factor, was published by Alter et al. in 1989 [3].

As is the case for sexual transmission, the risk of HCV transmission through seminal fluid is also controversial. Risk factors that may increase the probability of transmission are the type of relationship, since monogamic couples tend to present lower transmission rates than individuals reporting sex with multiple partners, sexual relations that involve trauma, co-infection with acquired immunodeficiency virus (HIV), partners using drugs, associated sexually-transmitted diseases, paid sex, and a long-term relationship (>10 years) with an HCV-positive partner [4-6].

The direction of sexual transmission of HCV from men to women has been reported by Rooney and Gilson [7], who showed that the estimated risk of HCV infection is 3.7 times higher in women with HCV-positive partners. Cavalheiro et al. [8] studied a series of 24 couples with a diagnosis of hepatitis C; there was an average viral similarity of $98.3 \%$ for $22 / 24(91.7 \%)$ couples. In that study, the NS5b-HCV region was chosen for phylogenetic analysis. Nine couples attracted attention because the women did not report any risk factor for acquisition of the virus, whereas all nine men reported one or more risk factors. In this case, the average genomic similarity was $98 \%$. That study supports the hypothesis of infection from men to women.

Received on 26 May 2008; revised 10 August 2008.

Address for correspondence: Dr. Norma de Paula Cavalheiro, Ph.D. Av. Dr. Enéas de Carvalho Aguiar, 500, $1^{\circ}$ andar, sala 12. Bairro Cerqueira César. Zip code: 05403-000. São Paulo - SP, Brazil. Phone/fax: (11) 3085-1601. E-mail: norma@usp.br.

The Brazilian Journal of Infectious Diseases 2008;12(5):358-361 (C) 2008 by The Brazilian Journal of Infectious Diseases and Contexto Publishing. All rights reserved.
Studies analyzing semen by molecular biology techniques have reported difficulty in eliminating natural inhibitors present in the sample, which frequently leads to false-negative results [9]. Cassuto et al.[10], in a study of semen from 35 men, reported difficulty in removing inhibitors during HCV-PCR, with only five men testing positive, suggesting false-negative results. Various investigators have been able to detect HCV in semen, while others could not. The difficulty in isolating this virus from body fluids, especially semen, is probably due to the presence of inhibitors and the lack of standardized techniques and protocols for RNA extraction and reverse transcription and polymerase amplification (RT-PCR); these factors may contribute to false-negative results $[9,11]$.

Our objective was to investigate whether HCV is present in semen samples from infected patients.

\section{Material and Methods}

Patient Selection

Between June and December 2004, male patients with a clinical and laboratory diagnosis of HCV infection were recruited from the Hepatitis Outpatient Clinic of the Infectious Diseases Department. All recruited patients signed an informed consent agreement.

\section{Blood and Semen Collection and Preparation}

Blood was collected from patients into $10 \mathrm{~mL}$ dry vacuum tubes, after an 8 to 12-h fast. Semen samples were obtained by self-masturbation, after a period of sexual abstinence of at least three days. Blood and semen samples were stored at $80^{\circ} \mathrm{C}$ until the time of use.

In addition to an aliquot of total semen, fractions were isolated on 90 and 45\% Percoll gradients. The samples were centrifuged for $30 \mathrm{~min}$. at 3,000 rpm, and the following three phases were obtained: seminal plasma, leukocytes and spermatozoa. 
Serum

All serum samples were analyzed with the qualitative Amplicor HCV test, version 2.0 (Roche Diagnostics Corp., Indianapolis, IN, USA). If positive, the blood samples were genotyped with INNO-LiPA HCV II kit (INNO-LIPA HCV, Versant Bayer, Tarrytown, NY, USA).

\section{Semen}

All semen samples were analyzed with the qualitative Amplicor HCV test, version 2.0 (Roche Diagnostics Corp., Indianapolis, IN, USA). After the end of the PCR-HCV reaction, the presence of HCV in semen samples was revealed by two methods: i) electrophoresis in agarose gel and ii) Roche Amplicor test by colorimetric determination.

\section{Electrophoresis Agarose Gel Detection}

The PCR-HCV products were detected by $2 \%$ Agarose Gel electrophoresis, stained with ethidium bromide and observed under ultraviolet light[13-15].

\section{Amplicor HCV Test, $v 2.0$}

The Amplicor HCV Test, v 2.0, is an RT-PCR in a manual, microwell format that amplifies a 244-nucleotide segment of the 5'-UTR of the HCV genome. The test was performed at all sites according to manufacturer's instructions, as previously described. HCV RNA optical density (OD) values were interpreted as follows: $<0.3$, negative; $\geq 0.3$ and $<1.0$, equivocal; and $\geq 1.0$, positive. An OD value of 0.3 was used as the cutoff for the internal control RNA. Any specimen with an OD value $<0.3$ for both HCV and internal control wells was considered to be inhibited[12].

\section{HCV Genotyping by the Line Probe Assay (LiPA)}

RNA was isolated from serum and 5'-UTR genotyping was performed with the INNO-LiPA HCV II kit (INNO-LIPA HCV, Versant Bayer, Tarrytown, NY, USA), according to manufacturer's instructions. Briefly, the 5'-UTR region was amplified with biotinylated primers. The biotin-labeled PCR products were then reverse hybridized to specific probes attached to nitrocellulose strips, and the results were developed as a purple precipitate that formed a positive line on the strip. The HCV type was deduced on the basis of the patterns of hybridizing bands using the LiPA interpretation chart[16].

\section{Results}

The mean age of the 13 patients was 40.8 years (range: 28 50, median: 45 years). The mean time since the diagnosis of HCV infection was 7.15 years (range: 2-14, median: 7 years).

\section{Serum}

Analysis was made of the same HCV-PCR product by the Roche Amplicor method and agarose gel electrophoresis with ethidium bromide staining; all serum samples tested positive by these two techniques, i.e., all patients presented viremia.
Semen

The products analyzed with the Amplicor HCV test and revealed by agarose electrophoresis gel detection were negative for all samples of total semen and fractions (spermatozoa, leukocytes and seminal plasma).

The same semen and seminal fractions (52 samples) analyzed by optical density (Roche Amplicor method) revealed 45 (86.5\%) of the results to be inhibited. Negative results were detected for one $(1.9 \%)$ total semen sample, one $(1.9 \%)$ leukocyte and 4 (7.7\%) seminal plasma fraction. Only one (1.9\%) sample of the spermatozoon fraction was positive.

\section{Discussion}

The inhibition of HCV-PCR in semen samples was clearly and unquestionably demonstrated, with 45 (87\%) of the 52 reactions involving total semen and fractions, spermatozoa, leukocytes and seminal plasma presenting inhibited results (Table 3). Amplicor HCV qualitative tests have an internal control, permitting the evaluation of the efficiency of the tests. In contrast, when the products of PCR (Amplicor HCV qualitative tests, v. 2.0 (Roche Diagnostics) were examined on the agarose gel with ethidium bromide staining, all samples tested negative. False-negative results were obtained with the in-house nested HCV-PCR method used in this preliminary study (data not shown). The presence of HCV-PCR inhibitors in semen masks the results and impairs their interpretation, a fact explaining the wide disparity in HCV detection rates reported in the international literature, which vary from 0 to $36 \%[10,11,17-25]$.

Our results support the hypothesis of the presence of $\mathrm{HCV}$ in semen samples from infected patients and also indicate the need for more sensitive tests and/or laboratory measures that remove HCV-PCR inhibitors so that reliable results can be obtained. Analysis of the HCV-PCR products by electrophoresis of an agarose gel and ethidium bromide staining apparently yielded false-negative results for all the semen samples. The commercial Roche Amplicor test demonstrated interference from inhibitors present in the semen samples, because it uses an internal control that guarantees the efficacy of the reaction; but it was unable to eliminate the inhibitors.

According to Abou-Setta [26] the contradictory results of HCV-PCR in semen can be explained by i) the different techniques used, ii) different HCV-PCR sensitivities, and iii) presence of inhibitors in semen that lead to false-negative results. Furthermore, this author reported that viral concentrations in semen samples go through rapid variations and indicated that inhibition might be due to the action of RNases or lipoperoxidase. The enzyme Taq polymerase may be inhibited by seminal fluid enzymes, lactoferrin, peroxidase or zinc residues [26].

The two main adaptations needed for testing semen are elimination of PCR inhibitors, especially frequent in seminal plasma, and the use of small sample volumes. The choice of the extraction protocol is critical[9]. 
Table 1. Distribution of the patients according to risk factors for the acquisition of HCV.

\begin{tabular}{lcc}
\hline Epidemiology & $\begin{array}{c}\text { No. of } \\
\text { patients }\end{array}$ & $\%$ \\
\hline Use of injectable and/or inhaled drugs & 6 & $42.8 \%$ \\
Blood transfusion & 4 & $28.6 \%$ \\
Unknown & 4 & $28.6 \%$ \\
\hline
\end{tabular}

Table 2. Distribution of the patients according to HCV subtype.

\begin{tabular}{lc}
\hline Genotype & No. of patients (\%) \\
\hline $1 \mathrm{a}$ & $5(38.5 \%)$ \\
$1 \mathrm{~b}$ & $1(7.7 \%)$ \\
$1 \mathrm{a} / 1 \mathrm{~b}$ & $2(15.4 \%)$ \\
$2 \mathrm{~b}$ & $2(15.4 \%)$ \\
3a & $3(23.0 \%)$ \\
Total & $13(100 \%)$ \\
\hline
\end{tabular}

Information regarding the quantity of circulating virus is important; it helps increase the probability of HCV detection in semen and demonstrates the potential of sexual transmission. Nyamaty et al. [27] showed that the quantity of virus in blood is correlated with the virus in semen. The distribution of HCV viral types was compatible with the prevalence that was previously reported for Brazil, with most of the (infected) population being infected with HCV genotype 1, followed by genotypes 3 and 2 (Table 2) [28]. On average, 40 to $50 \%$ of patients infected with HCV indicate no specific source of acquisition of the virus [26]. We had 28.6\% unknown risk factors (Table 1).

This preliminary study of semen samples by HCV-PCR indicates the need for new research protocols in order to obtain more reliable results. Other laboratory resources or even new techniques for viral detection should be tested for the evaluation of semen samples so that the results better correspond to reality.

\section{Acknowledgements}

We thank the Hepatitis Outpatient Clinic of the Infectious Diseases Department, University Hospital, University of São Paulo.

\section{References}

1. Flamm S.L. Chronic hepatitis $C$ virus infection. JAMA 2003;289(18):2413-7.

2. Brook M.G. Sexually acquired hepatitis. Sex Transm Infect 2002;78(4):235-40.

3. Alter M.J., Coleman P.J., Alexander W.J., et al. Importance of heterosexual activity in the transmission of hepatitis $B$ and non-A, non-B hepatitis. JAMA 1989;262(9):1201-5.

4. Terrault N.A. Sexual activity as a risk factor for hepatitis C. Hepatology 2002;36(5 Suppl 1):S99-105.

5. Clarke A., Kulasegaram R. Hepatitis C transmission - where are we now? Int J STD AIDS 2006;17(2):74-80.

6. Filippini P., Coppola N., Scolastico C., et al. Does HIV infection favor the sexual transmission of hepatitis C? Sex Transm Dis 2001;28(12):725-9.

7. Rooney G., Gilson R.J. Sexual transmission of hepatitis C virus infection. Sex Transm Infect 1998;74(6):399-404.

8. Cavalheiro N., Tengan F., Melo C., et al. P.224 Hepatitis C: interfamilial or sexual transmission? J Clin Virol 2006;36(Suppl 2):S131.

9. Pasquier C., Souyris C., Moinard N., et al. Validation of an automated real-time PCR protocol for detection and quantitation of HIV and HCV genomes in semen. J Virol Methods 2006;137(1):156-9.

10. Cassuto N.G., Sifer C., Feldmann G., et al. A modified RT-PCR technique to screen for viral RNA in the semen of hepatitis C virus-positive men. Hum Reprod 2002;17(12):3153-6.

11. Pekler V.A., Robbins W.A., Nyamathi A., et al. Use of versant TMA and bDNA 3.0 assays to detect and quantify hepatitis C virus in semen. J Clin Lab Anal 2003;17(6):264-70.

12. Lee S.C., Antony A., Lee N., et al. Improved version 2.0 qualitative and quantitative AMPLICOR reverse transcription-PCR tests for hepatitis $C$ virus RNA: calibration to international units, enhanced genotype reactivity, and performance characteristics. J Clin Microbiol 2000;38(11):4171-9.

13. Smith D.B., Lawlor E., Power J., et al. A second outbreak of hepatitis $C$ virus infection from anti-D immunoglobulin in Ireland. Vox Sang 1999;76(3):175-80.

14. Garson J.A., Ring C., Tuke P., Tedder R.S. Enhanced detection by PCR of hepatitis C virus RNA. Lancet 1990;336(8719):878-9.

Table 3. Results of HCV-PCR with the Roche Amplicor test.

\begin{tabular}{llcccc}
\hline Patient & Serum & Total semen & Spermatozoa & Leukocytes & Seminal plasma \\
\hline 1 & Positive & Inhibition & Inhibition & Inhibition & Inhibition \\
2 & Positive & Inhibition & Inhibition & Inhibition & Inhibition \\
3 & Positive & Inhibition & Inhibition & Inhibition & Negative \\
4 & Positive & Negative & Positive & Negative & Negative \\
5 & Positive & Inhibition & Inhibition & Inhibition & Inhibition \\
6 & Positive & Inhibition & Inhibition & Inhibition & Inhibition \\
7 & Positive & Inhibition & Inhibition & Inhibition & Inhibition \\
8 & Positive & Inhibition & Inhibition & Inhibition & Inhibition \\
9 & Positive & Inhibition & Inhibition & Inhibition & Negative \\
10 & Positive & Inhibition & Inhibition & Inhibition & Inhibition \\
11 & Positive & Inhibition & Inhibition & Inhibition & Negative \\
12 & Positive & Inhibition & Inhibition & Inhibition & Inhibition \\
13 & Positive & Inhibition & Inhibition & Inhibition & Inhibition \\
\hline
\end{tabular}


15. Chomczynski P., Sacchi N. Single-step method of RNA isolation by acid guanidinium thiocyanate-phenol-chloroform extraction. Anal Biochem 1987;162(1):156-9.

16. Stuyver L., Wyseur A., van Arnhem W., et al. Second-generation line probe assay for hepatitis $\mathrm{C}$ virus genotyping. J Clin Microbiol. 1996;34(9):2259-66.

17. Hsu H.H., Wright T.L., Luba D., et al. Failure to detect hepatitis C virus genome in human secretions with the polymerase chain reaction. Hepatology 1991;14(5):763-7.

18. Fried M.W., Shindo M., Fong T.L., et al. Absence of hepatitis C viral RNA from saliva and semen of patients with chronic hepatitis C. Gastroenterology 1992;102(4 Pt 1):1306-8.

19. Terada S., Kawanishi K., Katayama K. Minimal hepatitis C infectivity in semen. Ann Intern Med 1992;117(2):171-2.

20. Caldwell S.H., Sue M., Bowden J.H., et al. Hepatitis C virus in body fluids after liver transplantation. Liver Transpl Surg 1996;2(2):124-9.

21. Semprini A.E., Persico T., Thiers V., et al. Absence of hepatitis $C$ virus and detection of hepatitis $G$ virus/GB virus $C$ RNA sequences in the semen of infected men. J Infect Dis 1998;177(4):848-54.
22. Debono E., Halfon P., Bourliere M., et al. Absence of hepatitis C genome in semen of infected men by polymerase chain reaction, branched DNA and in situ hybridization. Liver 2000;20(3):257-61.

23. Levy R., Tardy J.C., Bourlet T., et al. Transmission risk of hepatitis $\mathrm{C}$ virus in assisted reproductive techniques. Hum Reprod. 2000;15(4):810-6.

24. Liou T.C., Chang T.T., Young K.C., et al. Detection of HCV RNA in saliva, urine, seminal fluid, and ascites. J Med Virol 1992;37(3):197-202.

25. Leruez-Ville M., Kunstmann J.M., De Almeida M., et al. Detection of hepatitis $C$ virus in the semen of infected men. Lancet 2000;356(9223):42-3.

26. Abou-Setta A.M. Transmission risk of hepatitis $C$ virus via semen during assisted reproduction: how real is it? Hum Reprod 2004;19(12):2711-7.

27. Nyamathi A., Robbins W.A., Fahey J.L., et al. Presence and predictors of hepatitis $\mathrm{C}$ virus RNA in the semen of homeless men. Biol Res Nurs 2002;4(1):22-30.

28. Cavalheiro N. de P., Barone A.A., Tengan F.M. HCV serotypes in Brazilian patients. Int J Infect Dis 2002;6(3):228-32. 